\title{
Los primeros 15 años de la Revista de Medicina y Cine, un compro- miso con el humanismo médico
}

\author{
Wilson ASTUDILLO ALARCÓN
}

\section{The first $\mathbf{1 5}$ years of Journal of Medicine and Movies, a commitment to medical humanism}

Paliativos Sin Fronteras, San Sebastián (España).

Autor para correspondencia: Wilson Astudillo Alarcón. Correo electrónico: wastudillo49@gmail.com

Recibido el 22 de agosto de 2019; aceptado el 2 de septiembre de 2019.

Cómo citar este artículo: Astudillo Alarcón W.Los primeros 15 años de la Revista Medicina y Cine, un compromiso con el humanismo médico. Rev Med Cine [Internet] 2020;16(2):73-5.

DOI: http://dx.doi.org/10.14201/rmc20201617375

Los lectores de la Revista de Medicina y Cine (RMC), que celebra 15 años de existencia, damos a esta publicación médico humanista nuestra mayor enhorabuena, porque ha cumplido plenamente con los objetivos propuestos por sus editores y fundadores José Elías García Sánchez y Enrique García Sánchez ${ }^{1}$ de: "Escudriñar en la amplísima producción cinematográfica en relación con las ciencias de la salud; analizar las películas con ojos profesionales, tanto en la vertiente sanitaria como cinematográfica; formar, informar, despertar el espíritu crítico y la capacidad de observación y facilitar la expresión de las capacidades e inquietudes de un segmento de las profesiones sanitarias y de colectivos ajenos a la sanidad que quieran hacer una valoración de la medicina en el cine".

Un gran desafío de la enseñanza es proporcionar el conocimiento en una forma que llegue más directamente al destinatario a través de ofrecerle otros complementos como una selección de películas documentales o secuencias que narran historias reales o ficticias para que puedan estudiarlos y favorecer su espíritu crítico y su posible aplicación práctica. Estamos acostumbrados a narrar lo que nos ha sucedido y consideramos importante, más aún cuando enfermamos, que es una experiencia traumática que no solo afecta al paciente sino también a su familia. Todos somos seres de historias y habitamos, según Flichtentrel2 ${ }^{2}$ en una atmósfera cargada con infinitas historias que llamamos "cultura". La forma cómo lo hacemos indica quiénes somos, cómo somos y cuáles son los valores que dan fundamento a nuestra existencia. Para V. Woolf, "la enfermedad remueve la tierra donde está plantado un árbol; deja al descubierto las raíces y se ve lo profundas y fuertes que son". Las narraciones colocan al ser humano en el centro de su atención, lo hacen único. Algunas películas nos enseñan a ver lo que nos rodea y nos permiten vivir experiencias de vidas ajenas, a plantear las cuestiones de forma serena, a intuirlas, a vibrar por empatía en consonancia con los demás y aproximar soluciones que han de ser consensuadas con el enfermo. La compasión implicaría una acción, una respuesta activa ante el sufrimiento de otro para que deje de padecerlo3-6.

Las historias que vemos en el cine sobre cómo una persona reacciona ante la enfermedad y ante la posible muerte son capaces de generar conocimientos, tanto literarios como bioéticos y de favorecer las habilidades de comunicación que nos ayudarán a sentirnos más humanos, a tener una mayor consciencia de la realidad, a ver todo de una forma más empática y a ser más receptivos a los demás y a sus circunstancias, en particular cuando padecen enfermedades que alteran su calidad de vida y supervivencia ${ }^{3-6}$. Una de las grandes virtudes de las películas para I. Marzabal7, "es su capacidad de contextualización, su atención al detalle, a lo efímero, a lo singular, a lo contingente, su posibilidad de hacer que el arquetipo, o la idea se encarne, se haga carne, adquiera rostro. Rostro humano", por lo que el cine, "el arte de la democracia" en tanto que espectáculo de masas y socializador del conocimiento, puede ser procurador de experiencias y un factor que puede beneficiar a diferentes campos de las ciencias de la Salud y a los propios sanitarios ${ }^{2}$. 
García Sánchez ${ }^{8}$ e Icart ${ }^{9}$, aconsejan que la película completa o sus fragmentos a usarse en la docencia deben ser analizados con profundidad para valorar qué hay de realidad y de invención, porque el cine no documental sigue siendo ficción y aunque se acerque mucho a la realidad, tiene muchos errores e intereses básicamente comerciales que priman sobre los aspectos científicos. Hay que, también, motivar al estudiante para indagar, buscar información complementaria y analizar la verosimilud (validez y transferibilidad) porque incluso los errores y las divergencias pueden ser útiles como contraejemplos ${ }^{9}$. Para García Sanchez et al. ${ }^{8}$, profundizar y ser crítico y darse cuenta de los errores y comentarios no es menos profesional ni formativo.

La Revista de Medicina y Cine ha sido desde su nacimiento en la Universidad de Salamanca un faro en la cultura médica humanista que se ha nutrido de excelentes aportaciones de muchos ilustres profesores y observadores, en particular sobre el trastorno existencial que provoca la enfermedad y el comportamiento humano, que han enriquecido a todos los que la hemos conocido. Ha sido especialmente plausible el esfuerzo de RMC para mejorar la comprensión de los enfermos y de sus familias, dado que la medicina se mueve entre las ciencias biológicas, las técnicas y las ciencias sociales y humanas, entre el conocimiento desapegado y la práctica compartida y compasiva, y existen muchos elementos más allá del desarrollo técnico que permiten integrar mejor los diversos conocimientos, prácticas y valores para cuidar al enfermo protegiendo su seguridad ${ }^{10}$. Ha facilitado el desarrollo de numerosos cursos universitarios con un material singular para la investigación relacionada con la educación, mentalización y divulgación en el campo de la salud. Sus efectos están siendo muy positivos por su relación con el arte, la literatura, bioética, historia y la música, debido a que las humanidades trabajan también sobre los sentimientos y la conciencia y nos ayudan a diseñar marcos de sentido y de valores que permiten a las sociedades comprenderse a sí mismas y orientarse hacia un auténtico progreso ${ }^{11}$.

Su contenido tan bien presentado sobre múltiples temas constituye una formidable base documental sobre el humanismo médico que puede aportar un gran beneficio a los lectores, no solo por el placer de conocer sino para mejorar personalmente, lo que hace a RMC verdaderamente terapéutica y que sea la base de muchas investigaciones futuras ${ }^{11}$. Ya cuenta con una legión cada vez mayor de seguidores, más de 1.500 .000 en estos 15 años, que se han descargado más de 250.000 artículos, y se ha convertido en un espacio para la reflexión y la experiencia práctica y en el foro ideal para propagar el uso académico del cine y ciencias y artes anexas ${ }^{12}$.
Los estudiantes pueden adquirir gracias a la RMC la posibilidad de dialogar y trabajar algunas habilidades en relación con el humanismo médico y muchos de sus principios, tales como dignidad, libertad, responsabilidad y la seguridad del enfermo, que les servirán en el ejercicio profesional, relación médico-paciente, empatía, respeto a su autonomía y confianza, que les acompañarán siempre ${ }^{4,11}$. Puede ser útil también para la educación de los pacientes y familias sobre su seguridad si bien se requiere un aprendizaje continuo del equipo sanitario sobre cómo interaccionan los diversos componentes del sistema, lo que implica poner en práctica actuaciones con demostrada efectividad para reducir la probabilidad de aparición de fallos y errores y aumentar su detección cuando ocurren, mitigar sus consecuencias, notificarlos e investigarlos para evitar su reaparición ${ }^{13}$.

Nuestra gratitud a José Elías y a Enrique García Sánchez, así como a su maravilloso equipo por el trabajo realizado en base a su amor por el cine y a la docencia médica, así como a toda la pléyade de brillantes compañeros que han contribuido a su esplendor. Creemos que bajo la influencia de la RMC se desarrollarán nuevos campos de investigación ${ }^{9}$ con muchos resultados positivos para la sanidad, pero para su continuidad y que conserve su carácter gratuito y vitalidad requiere una mayor estabilidad económica que se podría lograr con una donación anual de sus seguidores, una vez que la Universidad de Salamanca, que mantiene el copyright, no puede hacerlo. Para ello es conveniente y propongo que exista en su web un espacio para donaciones. Las ideas que transforman y que mantienen los valores humanos necesitan también apoyo material.

\section{Referencias}

1. García Sanchez JE, García Sánchez E. Hacia la segunda década de la Revista de Medicina y Cine. Rev Med Cine 2014; 10 (4).155-6.

2. Flichtentrel D. Un encuentro entre medicina y literatura. Rev Med Cine 2015;11(4):244.

3. Gómez Cordoba Al, Estrada H. El cine y la comunicación de malas noticias. Rev Med Cine 2016; 12(1):21-32.

4. Ogando Díaz B, Tejera Torroja E. Más allá de la empatía: la mirada compasiva en el cine. Rev Med Cine 2015; 11(1):19-33.

5. Astudillo Alarcón W, Mendinueta Aguirre C. El cine en la docencia de medicina: paliativos y bioética. Rev Med Cine 2007;3(1):32-41.

6. Peña Bandrés I. Cuidados paliativos y cine: una actualización comentada de la producción relacionada desde mediados del siglo pasado hasta la última década del actual. Rev Med Cine 2018;14(4):259-65.

7. Marzabal I. El cine, ¿Puede hacernos mejores... profesionales de la sanidad?: (en el décimo aniversario de la Revista de Medicina y Cine. Rev Med Cine 2014;10(4):149-150.

8. García Sánchez JE, García Sánchez E, García Moro M, Moratal Ibañez L. Medicina y cine. Ficción si, errores no. El valor de la crítica... y de la lupa. Rev Med Cine 2015;11(4):179-180.

9. Icart Isern MT. Medicina y cine para la docencia y la investigación. Rev Med Cine 2014; 10(2):51-2. 
10. Martínez Sabater A, Ballestar Tarin ML, Casal Angulo MC, Domínguez Romero A. La seguridad del paciente a través del análisis de Anatomía de Grey; temporada 6, capítulo 6. Vi lo que vi. Rev Med Cine 2016; 12(2):82-90.

11. Hidalgo A, Bordallo J. Cantabrana B. La Revista de Medicina y Cine, 15 años después. Una contribución al humanismo médico. Rev Med Cine 2019; 15(2):63-5.

12. Rodríguez Sánchez J.A. Una revista Terapéutica. Rev Med Cine 2014;10(4):153-4

13. García Moro M, García Sánchez JE, García Sánchez E, García Merino E. 15 años de la Revista de Medicina y Cine. Rev Med Cine 2019;15(1):1-2.
Wilson Astudillo Alarcón. Especialista en Neurología y en Medicina Familiar y Comunitaria. Coautor de varios libros de Medicina Paliativa entre ellos: Cuidados del enfermo en fase terminal y atención a su familia" Eunsa, 60 Edición (2018), Medicina Paliativa en niños y adolescentes, Paliativos sin Fronteras" (2015)..., y artículos sobre paliativos y cooperación internacional. Fundador y Presidente de Paliativos Sin Fronteras. wastudillo49@gmail.com; psf@paliativossinfronteras.org; www. paliativossinfronteras.org. 